\title{
Preparation and characterization of microcapsule containing epoxy resin and its self-healing performance of anticorrosion covering material
}

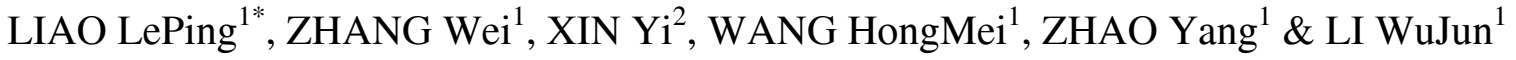 \\ ${ }^{1}$ National Key Laboratory for Remanufacturing, Academy of Armored Force Engineering, Beijing 100072, China; \\ ${ }^{2}$ Institute of Chemical Defence, Beijing 102205, China
}

Received June 12, 2009; accepted November 16, 2009

\begin{abstract}
Microencapsulated healing agents that possess adequate strength, long shelf-life, and excellent bonding to the host material are required for self-healing materials. The in situ encapsulation method is demonstrated over an order of magnitude size reduction for the preparation of urea-formaldehyde (UF) capsules filled with a healing agent, a mixture epoxy resin of the epoxy 711 and E-51. Capsules with diameters as small as about $100 \mu \mathrm{m}$ are achieved under the agitation rate of $800 \mathrm{r} \mathrm{min}^{-1}$. The capsules possess a uniform UF shell wall (4 $\mu \mathrm{m}$ average thickness). By using the analysis of scanning electronic microscope (SEM), thermal analysis (TG-DTA) and FTIR, the characteristics of the microcapsules were investigated respectively. Successful self-healing has been demonstrated for anticorrosion covering materials with microcapsules.
\end{abstract}

microcapsule, epoxy resin, urea-formaldehyde, self-healing materials

Citation: Liao L P, Zhang W, Xin Y, et al. Preparation and characterization of microcapsule containing epoxy resin and its self-healing performance of anticorrosion covering material. Chinese Sci Bull, 2011, 56: 439-443, doi: 10.1007/s11434-010-4133-0

Microcapsules and microcapsule technology have been widely employed in a series of fields. They have been utilized for sustained drug release [1,2], preservation of flavours $[3,4]$, electro phoretic display applications [5], intumescent fire retarding powders [6,7], biotechnology [8,9] and inorganic metal salt catalyst [10], etc. And there has been growing interest in use of microencapsulated materials for the healing of cracks generated during the service of polymer based composite materials [11,12]. The working principle is based on the fact that microcapsules containing healing agents were incorporated in the target polymer. These capsules rupture and release healing agents during crack formation and react with catalyst present in the composites leading to crack repair to restore mechanical properties. The poly (urea-formaldehyde) (PUF) microcapsules are synthesized for self-healing of materials. Now several

*Corresponding author (email: liaoleping.2007@163.com) groups synthesized the microcapsules with the dicyclopentadiene (DCPD) [13] and epoxy [14-16]. Although the catalyst of healing agents is more valuable, it is not suitable for the mass production and large-scale application. In this experiment, two kinds of epoxy resins (E-51 and 711), were used as the core materials of the microcapsule.

Now the main anticorrosion way is to use the paints to keep the surface of substrates for corrosion protection. However, during its service life, the anticorrosion coating undergoes changes in mechanical properties leading to the formation of microcracks which subsequently propagates and exposes substrate to atmospheric moisture and oxygen. This action results in accelerated disbonding of the paint and flake formation from the metal coating interface. Anticorrosion coatings can be considered as a special class of composite materials, so the concept of self-healing of cracks, as reported for composites, can be adopted for coatings to provide longer durability. 
Here, we report our works on the development of selfhealing coatings with microencapsulated healing agents. In this study, microcapsules with urea-formaldehyde as a shell and a mixture epoxy resin of the epoxy 711 and E-51 as the core were synthesized by in situ polymerization. The structure and performance of the microcapsules were analyzed. Efficacy of these microcapsules in healing of cracks in anticorrosion covering materials has been demonstrated.

\section{Materials and methods}

(i) Preparation of microcapsules. Microcapsules containing epoxy 711 and E-51 were prepared by in situ polymerization. At room temperature, $200 \mathrm{~mL}$ of deionised water was slowly added into $1000 \mathrm{ml}$ beaker. Under agitation $5 \mathrm{~g}$ urea, $0.5 \mathrm{~g}$ ammonium chloride and $0.5 \mathrm{~g}$ resorcinol were dissolved in solution. The $\mathrm{pH}$ was adjusted to approximately 3.5 by using the solution of hydrochloric acid in deionised water. Then $20 \mathrm{~mL}$ of mixture epoxy resin of the epoxy 711 and E-51 $\left(M_{711} / M_{\mathrm{E}-51}=1 / 5\right)$ was added slowly to form an emulsion and allowed to stabilize for $10 \mathrm{~min}$ under agitation. After stabilization, $12.67 \mathrm{~g}$ of $37 \mathrm{wt} \%$ aqueous solution of formaldehyde was added. The emulsion was heated and maintained at $60^{\circ} \mathrm{C}$ under stirring at $800 \mathrm{r} \mathrm{min}^{-1}$ for $4 \mathrm{~h}$. Contents were cooled to ambient temperature. Microcapsules from the suspension were recovered by filtration under vacuum. These were rinsed with water. The capsules were dried under vacuum.

(ii) Analysis of microcapsule size and shell morphology. Microcapsule size analysis was carried out with a particle size analyzer (Beckman Coulter LS 13320). Surface morphology, shell thickness and the size of microcapsules were determined by scanning electron microscopy (SEM, QUANTA200). Microcapsule was mounted on adhesive tape and ruptured with a razor blade for shell thickness measurement.

(iii) Analysis of microcapsule chemical construction. The chemical construction of microcapsule was analyzed by the Fourier Transform Infrared spectrophotometer (Bruker, EQUINOX 55). The solid shell material collected after extraction was mixed with $\mathrm{KBr}$, and then they were squeezed to the flake. After dried, the microcapsules mixed with $\mathrm{KBr}$ were grinded to the flake, which was analyzed by the infrared spectrophotometer. In the same way, the chemical construction of core materials (epoxy resin 711 and E-51) was analyzed.

(iv) Thermal analysis of microcapsules. Microcapsules were analyzed using thermal analysis (TG-DTA, NETZSCH STA 449C) in nitrogen environment with a sample weight of about $7.5 \mathrm{mg}$. Heating rate was maintained at $10 \mathrm{~K} / \mathrm{min}$ in the temperature range of $30-500^{\circ} \mathrm{C}$. The flux of nitrogen of the method is $60 \mathrm{~mL} / \mathrm{min}$.

(v) Salt spray experiment of anti corrosion paint with microcapsules. Corrode liquor preparation: $50 \mathrm{~g}$ sodium chloride was dissolved in deionised water. Then $0.26 \mathrm{~g}$
$\mathrm{CuCl}_{2} \cdot \mathrm{H}_{2} \mathrm{O}$ was added to the solution. The $\mathrm{pH}$ was adjusted to approximately $3.1-3.5$ by using glacial acetic acid.

Salt spray cabinet: temperature, $(50 \pm 2)^{\circ} \mathrm{C}$; spray measure, $1-2 \mathrm{~mL} / \mathrm{h} \cdot 80 \mathrm{~cm}^{2}$; relative humidity, $95 \%-100 \%$; continuing spray $120 \mathrm{~h}$.

Clean steel panels, with size of $3 \mathrm{~mm} \times 3 \mathrm{~mm} \times 35 \mathrm{~mm}$, were coated on one side by brush to obtain epoxy aluminum priming coating. The microcapsules and firming agent were incorporated in epoxy anticorrosion paint solution. After solidified, cross-cut was made on panels and kept at ambient of salt spray. A composition without microcapsules was prepared as a control. Specimens coated with both compositions were exposed for a period $120 \mathrm{~h}$ in salt spray cabinet for evaluation of corrosion protection.

\section{Results and discussion}

\subsection{Analysis of microcapsules size and shell morphology preparation of microcapsules}

The microcapsule size analysis was performed by using two different methods, SEM and a particle size analyzer (Beckman Coulter LS 13320). Figure 1 and Figure 2 show the SEM micrographs: (a) capsule shell thickness (b) size and shell morphology. The SEM images revealed that the capsules were spherical in shape, with non-porous shell wall. The surface of microcapsule is rough and scraggly, and it is composed of PUF nanoparticles protruding from the surface. In the micrographs, the size and shell thickness of microcapsules were also observed. The size was around 100 $\mu \mathrm{m}$; the shell thickness is around $4 \mu \mathrm{m}$. Figure 3 shows the particle size distribution of microcapsules. The microcapsule size is in a wide range of $20-200 \mu \mathrm{m}$. The reason is that the fluid flow around the propeller is turbulent; in the region of flow away from the propeller; many larger microeddies exist, and in the vicinity of the propeller blades, many smaller microeddies exist, which result in a wider length scale $[17,18]$. The microcapsule size can be controlled by adjusting agitation rate. In this study, most of the particles fall in the size range around $100 \mu \mathrm{m}$. This is quite satisfactory for the use in self-healing of material.

\subsection{Analysis of infrared spectroscopy}

It is seen from the FTIR spectra of shell material and urea-formaldehyde resin (Figure 4) that both are closely matching at the characteristic peaks of an N-H stretching vibration at $1554 \mathrm{~cm}^{-1}$, a $\mathrm{C}=\mathrm{O}$ stretching vibration at 1648 $\mathrm{cm}^{-1}$, and a $\mathrm{C}-\mathrm{H}$ stretching vibration at $1460 \mathrm{~cm}^{-1}$. C-N stretching vibrations are shown at 1286 and $1142 \mathrm{~cm}^{-1}$. The $\mathrm{O}-\mathrm{H}$ peak is shown as a broad absorption peak at 3400$3200 \mathrm{~cm}^{-1}$. This spectrum confirms that shell material is made of urea-formaldehyde polymer. The FTIR spectrum of urea-formaldehyde resin is also matching with spectrum reported in the literature. Spectra of microcapsule and the 
core materials have also been found matching (Figure 5) at characteristic peaks for $\mathrm{C}=\mathrm{O}$, saturated $\mathrm{C}-\mathrm{H}$, double methyl radical $-\mathrm{C}\left(\mathrm{CH}_{3}\right)_{2}$ and frame of benzene ring stretching vibrations. Besides the spectra of microcapsule have the same characteristic peaks of urea-formaldehyde resin (Figure 4(b), Figure 5(b)). In view of the above it is established that the core materials have been successfully encapsulated in urea-formaldehyde shell.

\subsection{Thermal stability of microcapsules}

The thermal stability of microcapsules plays an important role in their applications in self-healing composites materials. Figure 6 shows the TGA and DSC curve of microcapsule. In the DSC curve of microcapsules, there are two endothermic peaks and two exothermic peaks appeared. For the two endothermic peaks, the first endothermic one below $100^{\circ} \mathrm{C}$ is due to the evaporation of water and free formaldehyde. The second one at temperatures between 225 and $248^{\circ} \mathrm{C}$ is due to the decomposition of shell materials [19]. With respect to the two exothermic peaks, the first one at temperatures between 250 and $300^{\circ} \mathrm{C}$ is due to the polymerization reaction of core material. The second one is at $450^{\circ} \mathrm{C}$, which perhaps due to the continuous polymerization reaction of core material. The TGA curve of microcapsules

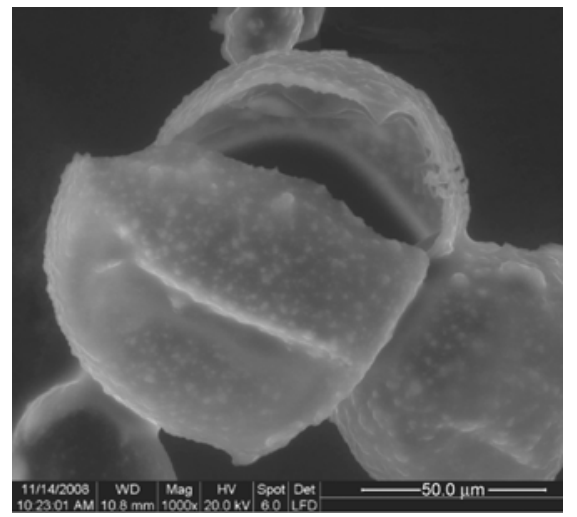

Figure 1 SEM micrographs: Shell thickness of microcapsules.

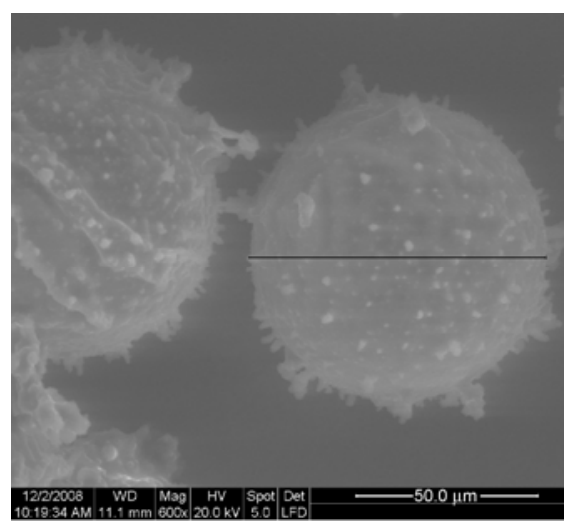

Figure 2 SEM micrographs: Size and shell morphology of microcapsules.

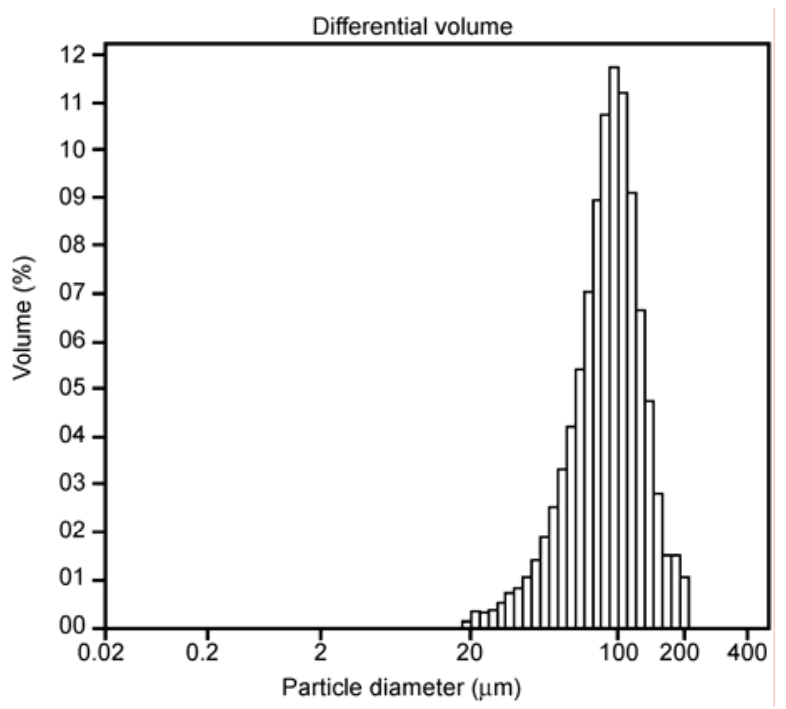

Figure 3 Particle size analysis of microcapsules.

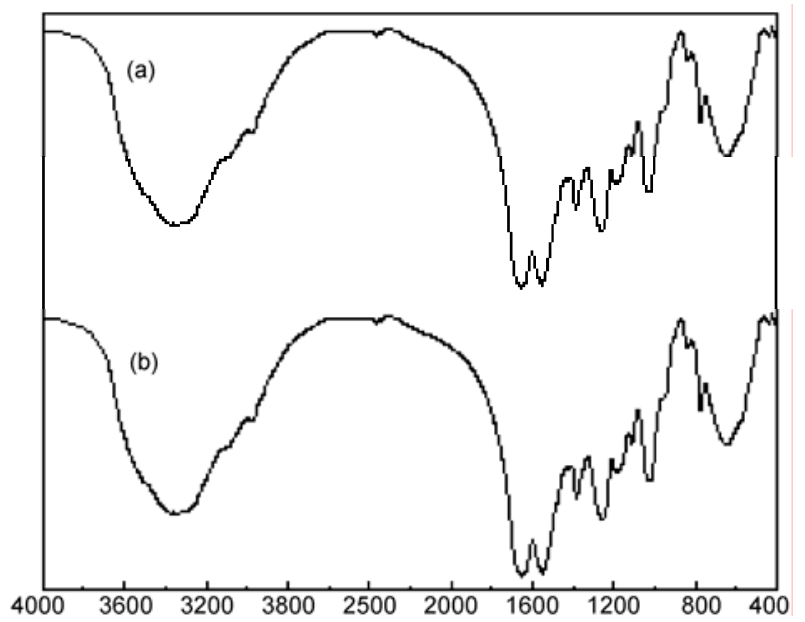

Figure 4 FTIR spectrums. (a) Shell material of microcapsule and (b) urea-formaldehyde resin.

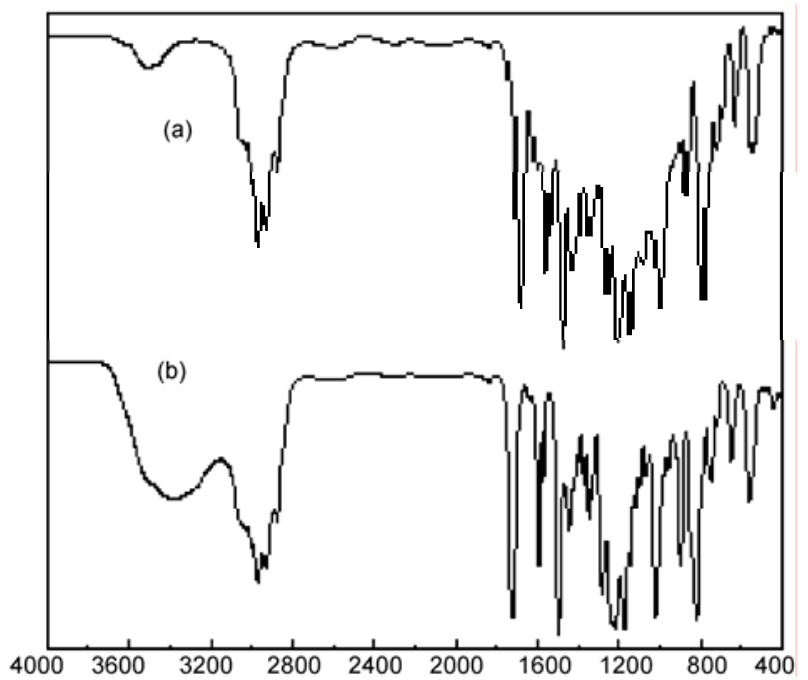

Figure 5 FTIR spectrum. (a) Core material and (b) microcapsule. 


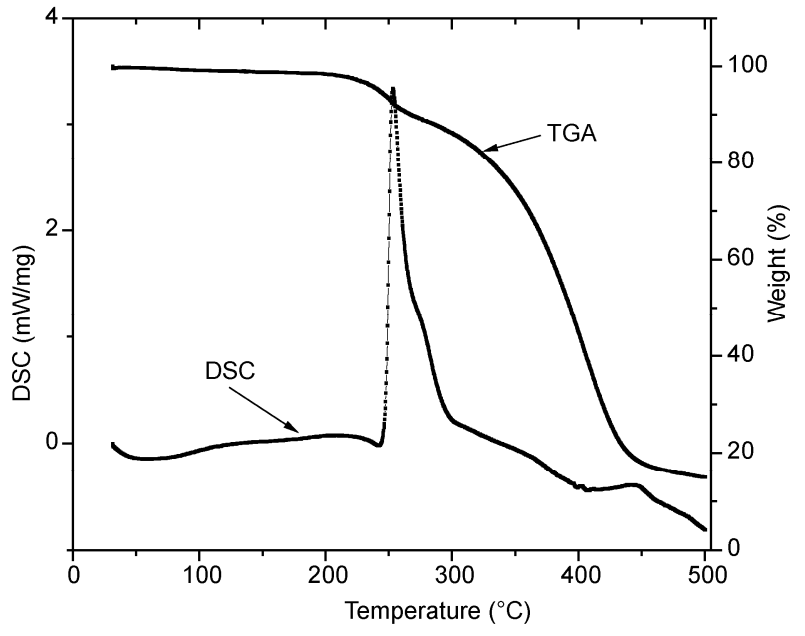

Figure 6 TG-DTA curve of microcapsules.

indicated that the weight between 30 and $200^{\circ} \mathrm{C}$ was mainly due to the removal of entrapped residual water and the elimination of free formaldehyde [20], it loss about $1.5 \%$. The weight loss at temperatures between 200 and $250^{\circ} \mathrm{C}$ was mainly due to the decomposition of the PUF wall shell. Due to the formation and the higher thermal stability of cross-linked polymer yielded by the core material, the weight loss of microcapsules in the range of $250-450^{\circ} \mathrm{C}$ tends to increase and the slope of TGA curve becomes big. The residuals undergo extensive fragmentation above $450^{\circ} \mathrm{C}$. Obviously, the microcapsules are chemically stable below $225^{\circ} \mathrm{C}$, indicating that the prepared microcapsules have a good thermal stability.

\subsection{Corrosion resistance of self-healing coating films}

Corrosion of metallic substrate takes place when moisture and oxygen are transported through the cracks to the metal-coating interface. Healing of cracks, thus, provides an effective method to prevent corrosion. Performance of self-healing material was assessed by exposing specimens coated with paint containing filled microcapsules to salt spray. Before exposure, coated surface was cross-cut up to the metal. Control specimens had the paint without microcapsules. Up to $120 \mathrm{~h}$ of exposure, specimens with paint containing microcapsules were found free from corrosion at the scribed lines (Figure 7(a)). Control panels, however, suffered from corrosion after $48 \mathrm{~h}$ of exposure (Figure $7(\mathrm{~b})$ ). Superior corrosion resistance performance of healed films is due to the reason that, linseed oil released from ruptured microcapsules filled the crack and formed a film through oxidative polymerization with atmospheric oxygen which prevented the ingress of moisture and oxygen and thus prevented corrosion.

\section{Conclusions}

Microcapsules filled with epoxy resin 711 and E-51 by in
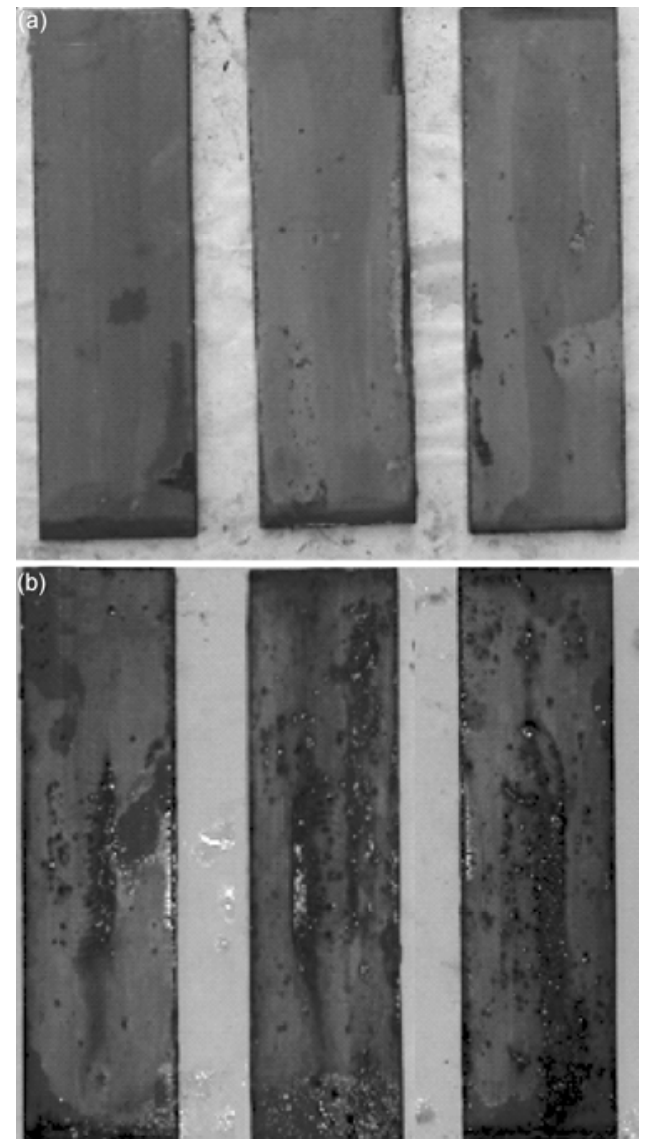

Figure 7 Salt spray performances of coatings (a) containing microcapsule (b) without microcapsule.

situ polymerization of urea-formaldehyde in an oil-in-water emulsion were prepared successfully. In this study, the microcapsules have the rough outer surface composed of PUF nanoparticles. The PUF microcapsules filled with epoxy resin 711 and E-51 have good storage at room temperature and basically exhibit a good chemical stability below $225^{\circ} \mathrm{C}$, which can withstand the moderate or high temperature processing of polymeric composites such as thermoset materials based on the epoxy resins.

From the salt spray experiment of anticorrosion paint with microcapsules, the microcapsules in anticorrosion coatings released healing material, which healed cracks efficiently with satisfactory anticorrosive properties during cracking. In general, this research provides appropriate microcapsules for the self-healing composites and the self-healing performance of the microcapsule on the polymeric composites was examined in the study.

This work was supported by the National Natural Science Foundation of China (50775222 and 50735006).

1 Eukaszczyk J, Urba P. Influence of the parameters of encapsulation process and of the structure of diisocyanates on the release of codeine from resinate encapsulated in polyurea by interfacial water promoted 
polyreaction. React Funct Polym, 1997, 33: 233-239

2 Tiyaboonchai W, Ritthidej G C. Development of indomethacin sustained release microcapsules using chitosan-carboxymethyl-cellulose complex coacervation. Songklanakarin J Sci Technol, 2003, 25: 245254

3 Park B J, Lee J Y, Sung J H, et al. Microcapsules containing electrophoretic suspension of $\mathrm{TiO}_{2}$ modified with poly (methyl methacrylate). Appl Phys, 2006, 6: 632-635

4 Saihi D, Vroman I, Girand S, et al. Microencapsulation of ammonium phosphate with a polyurethane shell. Part II. Interfacial polymerization technique. React Funct Polym, 2005, 64: 127-138

5 Girand S, Bourbigot S, Rochery M, et al. Flame retarded polyurea with microencapsulated ammonium phosphate for textile coating. Polym Degrad Stabil, 2005, 88: 106-113

6 Liu X D, Ataroshi T, Furuta T, et al. Microencapsulation of emulsified hydrophobic flavors by spray drying. Drying Technol, 2001, 19: 1361-1374

7 Park S J, Shin Y S, Lee J R. Preparation and characterization of microcapsules containing lemon oil. J Colloid Interface Sci, 2001, 241: 502-508

8 Orive G, Herna'ndez R M, Gasco'n A R, et al. Encapsulated cell technology: From research to market. Trends Biotechnol, 2002, 20: 382-387

9 Sukhorukov G, Fery A, Möhwald H. Intelligent micro- and nanocapsules. Prog Polym Sci, 2005, 30: 885-897

10 Ji H B, Kuang G J, Qian Y. Development of an immobilization method by encapsulating inorganic metal salts forming hollow microcapsules. Catal Today, 2005, 105: 605-611

11 Brown E N, Kessler M R, Sottos N R, et al. In situ poly (urea-for- maldehyde) microencapsulation of dicyclopentadiene. J Microencapsul, 2003, 20: 719-730

12 Lamaka S V, Zheludkevich M L, Yasakau K A, et al. $\mathrm{TiO}_{x}$ self-assembled networks prepared by templating approach as nanostructured reservoirs for self-healing anticorrosion pre-treatments. Electrochem Commun, 2006, 8: 421-428

13 White S R, Sottos N R, Geubelle P H, et al. Autonomic healing of polymer composites. Nature, 2001, 409: 794-800

14 Yuan L, Liang G Z, Xie J Q, et al. Preparation and characterization of poly (urea-formaldehyde) microcapsules filled with epoxy resins. Polymer, 2006, 47: 5338-5349

15 Yin T, Rong M Z, Zhang M Q, et al. Self-healing epoxy composites preparation and effect of the healant consisting of microencapsulated epoxy and latent curing agent. Compos Sci Technol, 2007, 67: 201212

16 Yuan L, Liang G Z, Xie J Q, et al. Thermal stability of microencapsulated epoxy resins with poly (urea-formaldehyde). Polym Degrad Stab, 2006, 91: 2300-2305

17 Taylor G I. The visocity of a fluid containing small drops of another fluid. Proc R Soc London Ser A, 1932, 138: 41-48

18 Dobetti L, Pantaleo V. Application of a hydrodynamic model to microencapsulation by coacervation. J Microencapsulation, 2002, 19: 139-151

19 Camino G, Operti L, Trossarelli L. Mechanism of thermal degradation of urea-formaldehyde polycondensates. Polym Degrad Stab, 1983, 5: 161-172

20 Zhang X X, Tao X M, Yick K L, et al. Structure and thermal stability of microencapsulated phase-change materials. Colloid Polym Sci, 2004, 282: 330-336

Open Access This article is distributed under the terms of the Creative Commons Attribution License which permits any use, distribution, and reproduction in any medium, provided the original author(s) and source are credited. 